\title{
Online teaching platform-starC and its applications in blended learning
}

\author{
Jiangbo Shu, a, Taihe Cao, , Xingfang Zhang ${ }^{1, c}$, Zhaoli Zhang ${ }^{1, d}$, Hai Liu ${ }^{1, e}$ and \\ Zhenhua $\mathrm{Li}^{1,2}$ \\ ${ }^{1}$ National Engineering Research Center for E-Learning, Central China Normal University, \\ 430079, Wuhan, China; \\ ${ }^{2}$ Network Center, China West Normal University, 637009, Nanchong, China \\ ashujiangbo@mail.ccnu.edu.cn, btaihec1@gmail.com, 'XingfangZhangZhang@gmail.com, \\ dzl.zhang@mail.ccnu.edu.cn, ehailiu0204@gmail.com, 'lizhenhua706@126.com
}

Keywords: Online learning, starC, blended learning, software engineering, teaching innovation.

\begin{abstract}
With the rapid development of information technology, blended learning as a worldwide hot topic in the field of education has attracted domestic and foreign researchers' attention including academic organizations, practitioners and education managers. In view of the shortage of the low efficiency in traditional offline learning due to the limitation of time and space, a novel application which contains offline learning and online learning was proposed. In our study, we selected the teaching of software engineering course and used starC as the supporting tool. Through analyzing learning behavior we found that students have higher learning enthusiasm and participation on blended learning than that on traditional offline learning. We can foresee that blended learning has a broad application prospect and huge development potential in the education.
\end{abstract}

\section{Introduction}

Blended learning as a new teaching mode has aroused people's wide attention both at domestic and overseas rapidly in recent years [1,2]. Blended learning has changed the traditional offline classroom learning mode and can satisfy the personalized needs of students [3, 4]. Our state has paid extensive attention on the use of blended learning to promote teaching innovation. In the year of 2012, the Ministry of Education released "The ten-year plan of Education Information Development (2011-2020)", on the basis of the education and information technology deeply integrated aiming to build new information-based teaching environment, optimize the mode of education and promote the education reform. In the process of exploration, a blended learning model which combined traditional offline teaching and virtual online teaching has gradually become popular [5-7]. Blended learning as a new teaching mode gives people who work in the course teaching reform hope and plays a key role in promoting education reform.

The traditional offline teaching exists inevitable shortcomings due to the limitation of time and space $[8,9]$. In the traditional offline classroom, teachers cannot provide sufficient learning resources for students and students complete the assignments under the provisions of the teachers. This style of learning cannot exert students' learning initiative and students in a state of passive learning. Due to the complexity of students' learning background, the traditional offline teaching is difficult to satisfy the needs of all students, therefore this reduces students' learning enthusiasm and it also limits the students' personalized learning [10]. In the traditional offline learning, teaching evaluation methods of student is simplex because of limitations of time, space and means. Teachers cannot give feedback and comments in a timely manner, it is hard to give effective multi-level and multi-dimensional feedback and comments to the students. Teachers will be unable to record students' complete performance in class at different aspects and stages, so it is hard to track students' learning progress and carry out formative evaluation [11].

Numerous education pioneers in different basic education schools and higher education universities have been actively exploring the use of blended learning mode, aiming to improve the 
effectiveness and quality of teaching $[12,13]$. Dias et al. studied the application of seamless learning strategies in the blended learning environment and explored ways to stimulate students' learning enthusiasm [14].Shin et al. studied the design of teaching in blended learning mode to improve the learning efficiency and present some opinions for students' knowledge construction [15]. Georgsen et al. studied the development and application of teaching resources for blended learning, and reviewed the principles and teaching methods in the blended learning mode [16]. The Central China Normal University has invested a lot of money and efforts in blended learning to explore the combination of online and offline learning style, and has achieved remarkable teaching results.

\section{The Tool Supporting Blended Learning}

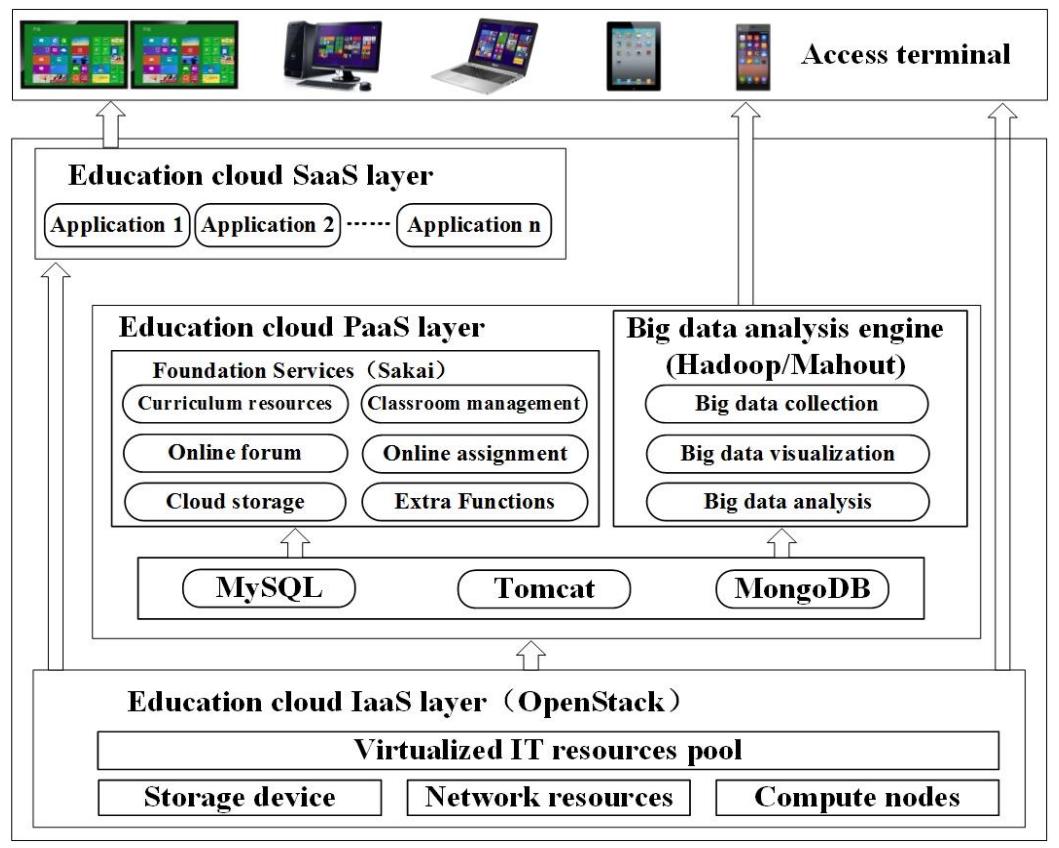

Fig. 1 Architecture of teaching Platform

Platform architecture. As shown in Fig. 1, the platform architecture consists of three education cloud layers. First of all, we use OpenStack to build a cloud infrastructure in IaaS layer, provide a virtual machine and cloud storage service for all the upper services or applications. Secondly, we use Sakai system and Hadoop/Mahout platform to build core business logic of the cloud class in the PaaS layer. Last but not least, we call the PaaS or IaaS layer services in SaaS layer to implement cloud class view for different types of user terminal. IaaS layer as the core of the cloud computing service mainly provides hardware infrastructure services, such as virtualized computing, storage, network and other IT resources for users on demand. PaaS layer plays an important role in the whole platform architecture, so we do our own efforts to focus on designing it. On the one hand, we extract the common demand of traditional online classroom to build infrastructure services based on the Sakai system. On the other hand, considering the platform serve for large-scale users demand and future development trend of the wisdom classroom, we collect, visualize and analyze the big data produced during the process of online learning. We can use the Hadoop and Mahout interface to realize the bid data analysis service and develop big data collection and visualization service independently. Through a service aggregation to realize unified platform view, SaaS layer provide services to the user directly.

Access terminal. Based on the platform architecture and open source technology framework, we have built an integrated teaching cloud classroom (called starC). The starC can support a variety of access terminals, including the teachers' electronic whiteboard, tablets, smart phones, laptops and ordinary PCs. Learning style based on starC can make study more intelligent and convenient, prompt 
students and teachers to access learning resources fully what they need anytime and anywhere in the campus. At the same time, learners can share harvest and confusion synchronous or asynchronous with teachers and learning companions in the process of learning. As shown in Fig. 2, teacher can use the electronic whiteboard on starC to carry out teaching activities, students can use the multi-terminal equipment on starC to carry out learning activity break through the limitation of time and place. They can learn course in the dormitory using laptop, access to knowledge in the laboratory using ordinary $\mathrm{PC}$, carry out cooperative learning in the playground using tablet, obtain learning information in the restaurant using smart phone and so on. The goal of blended learning is to create the education environment which can facilitate students to implement personalized learning using any terminal at any time and any place. In blended learning environment, students can create a seamless learning space based on starC, according to their individual needs and interests to find learning ways suitable for themselves, gradually improve their ability of knowledge acquisition, problem solving skills and creativity.

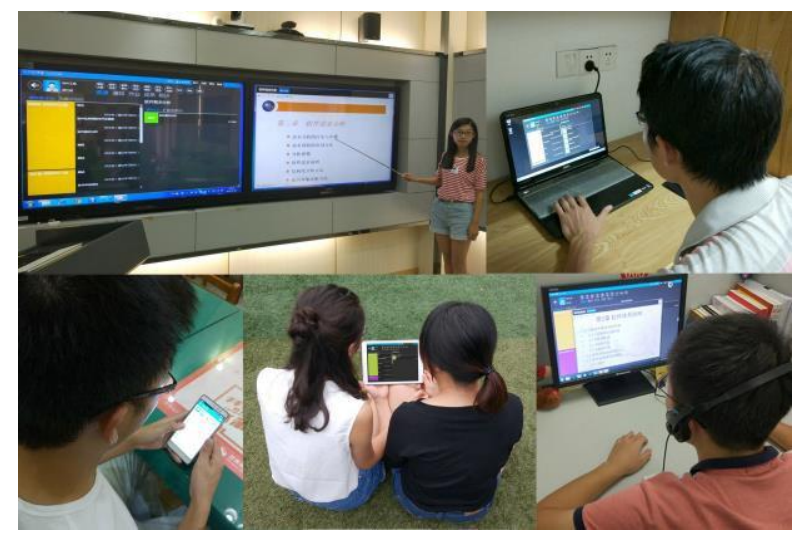

Fig. 2. A variety of access terminals

\section{Blended Learning in the Application of Software Engineering}

Curriculum construction. We can see from Fig. 3, this is the starC teaching platform for teachers, teachers can create their own curriculum, and at the same time teachers can access the curriculums which they are interested in within that course center. Combined with degree education for teaching needs in Central China Normal University, we have customized for its special cloud classroom version and carry out the application practice including all undergraduate and part of the graduate students. For the moment, we have created more than 2600 courses on starC, there are close to the 23000 users including teachers, students and teaching assistants. From the practical operation of nearly two years, the starC based on open source architecture run stability and the functions required to design. In addition, the starC has high scalability and extensibility in IaaS and PaaS layer and enables it to better meet the future expansion of the business and the growth of user scale.

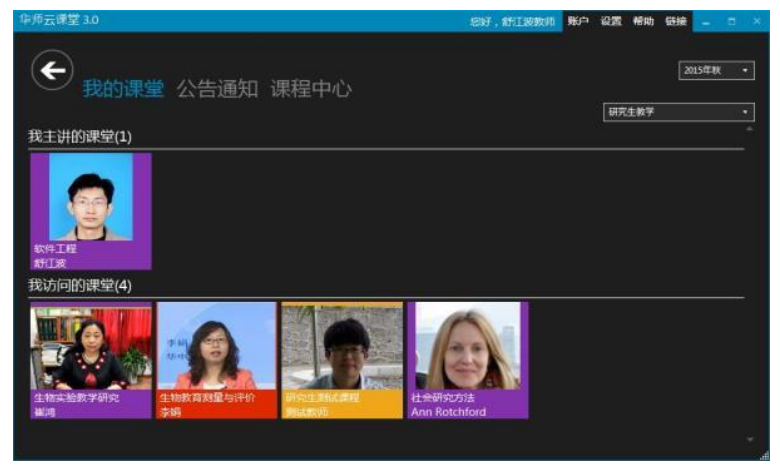

Fig. 3 The starC teaching platform for teachers

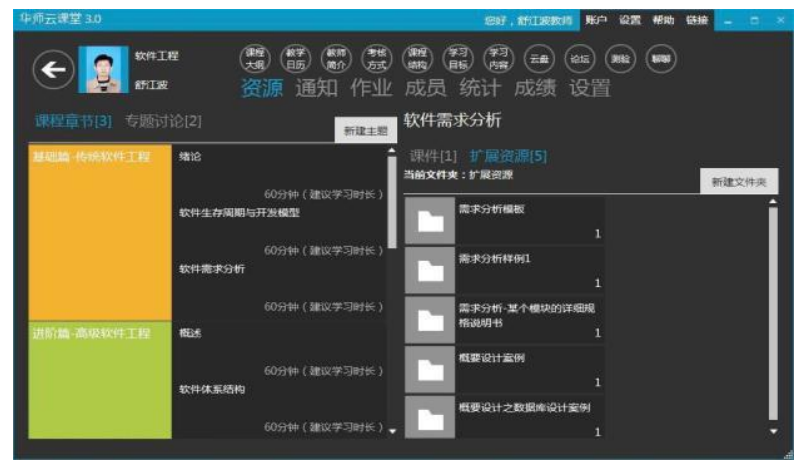

Fig. 4 Curriculum resources of StarC 
Practical application. This paper takes the teaching course of software engineering as an example to discuss about the blended learning. Before class, teacher uploads course-ware, documents and videos to the starC which will be used in the next class. As shown in Fig. 4, we can see from the picture, the curriculum resources of software engineering is divided into several teaching topics, and each teaching topic is divided into several teaching units. Each teaching units consists of the courseware and the expansion of resources which can be used in the traditional offline classroom and virtual online classroom. In class, teacher presents the contents of learning resource to the students and explains the important knowledge to the students. As shown in Fig. 5, this is partial members in the software engineering class, we can determine by ourselves when and where to learn online and students' learning process is not controlled by our teacher. Students won't be forced to attend every class and activity, the role of a teacher changed from leader to organizer. After class, our teacher arrange assignments on starC and students can download and finish it.

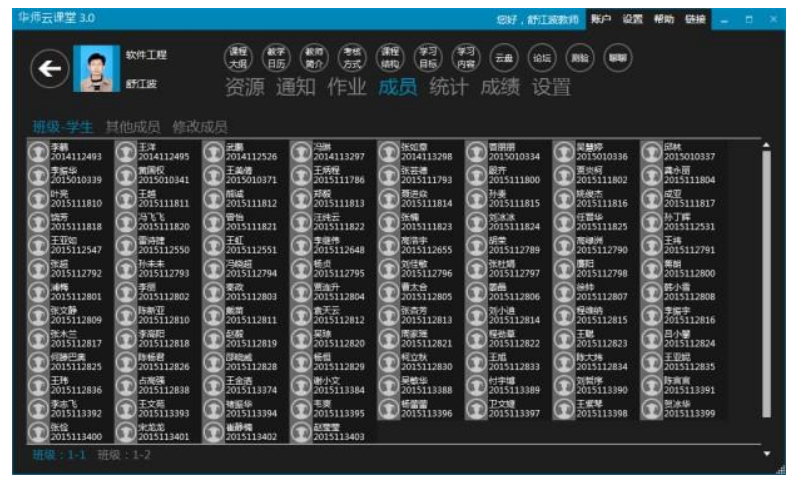

Fig. 5 Partial Member of starC

\section{Learning Statistics and Students' participation}

Learning statistics. With the help of information technology, the application of learning statistics has been popularized in teaching progress. In traditional offline learning, teachers cannot record each student's learning situation in the progress of learning in all details, resulting in the evaluation process of teachers to students only based on subjective mood. There is no doubt that it cannot describe their real behavior performance objectively and fairly. In view of this problem, we record personal big data of blended learning on starC and analyze those data to provide a basis for objective and fair evolution. According to the learning record of teaching in software engineering course as an example, we can see from Fig. 6, it can record the student's performance in the learning process. Through the analysis of the learning behavior, we can get the expression and action of learners, the application shows that learning behavior records have a relatively objective evaluation to students. It can also show students' historical performance, so as to stimulate students' learning enthusiasm and make up for their deficiencies.

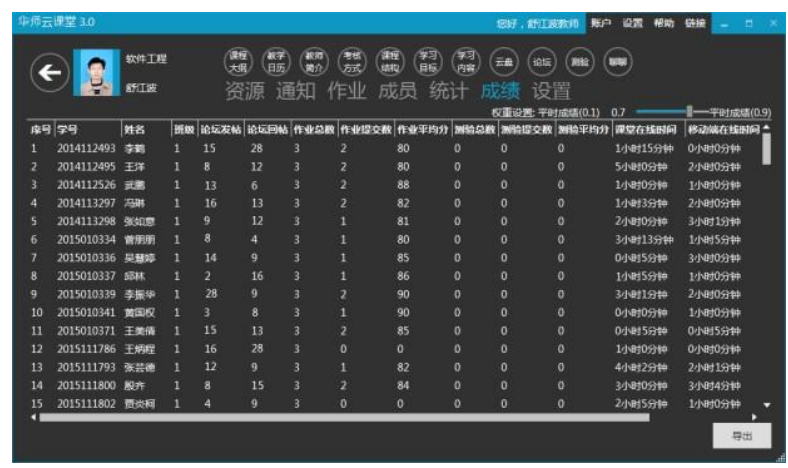

Fig. 6 Learning statistics of starC 
Students' participation. This paper is mainly based on the teaching of software engineering course from 2012 to 2015 . As mentioned above, we analyzed the data and evaluate the teaching effectiveness, at the same time we compared traditional offline learning and the blended learning from students' participation. We collected data from 53 students, 77 students, 105 students and 126 students from the software engineering in 2012, 2013, 2014 and 2015 respectively. Traditional offline learning is used in 2012 and 2013 while blended learning is used in 2014 and 2015. There are 34 teaching hours in the course. In the traditional offline learning, we divided the course into 13 weeks of classroom teaching and 4 weeks of project practice. While in the blended learning, there are 8 weeks of classroom teaching, 5 weeks of online learning and 4 weeks of project practice. As shown in Table 1, students' participation is based on class attendance and class discussion. The class discussion is mainly based on system access, classroom discussion, posts, replies, chatting and so on. As shown below, $R S$ represents number of required students, $T S$ represents total number of students, $W$ represents number of weeks, $A R$ represents number of weeks, $A R$ represents attendance rate and $A$ represents number of attendance, the definition of class sign in is:

$$
\begin{aligned}
& R S=T S^{*} W \\
& A R=A / R S
\end{aligned}
$$

\begin{tabular}{|c|c|c|c|c|c|c|c|c|c|}
\hline \multirow[t]{3}{*}{ Mode } & \multirow[t]{3}{*}{ Year } & \multirow{2}{*}{\multicolumn{3}{|c|}{$\begin{array}{l}\text { Class attendance } \\
\text { Class sign in }\end{array}$}} & \multicolumn{5}{|c|}{ Class discussion } \\
\hline & & & & & \multirow{2}{*}{$\begin{array}{l}\text { System } \\
\text { access }\end{array}$} & \multirow{2}{*}{$\begin{array}{l}\text { Classroom } \\
\text { discussion }\end{array}$} & \multirow[t]{2}{*}{ Forum } & \multirow[t]{2}{*}{ Chatting } & \multirow{2}{*}{$\begin{array}{l}\text { Response } \\
\text { papers }\end{array}$} \\
\hline & & $\mathrm{RS}$ & $\mathrm{A}$ & AR & & & & & \\
\hline Traditional & 2012 & 689 & 516 & $75 \%$ & null & 68 & null & null & 51 \\
\hline class & 2013 & 1001 & 726 & $73 \%$ & null & 87 & null & null & 73 \\
\hline Blended & 2014 & 840 & 620 & $74 \%$ & 423 & 176 & 105 & 302 & 105 \\
\hline class & 2015 & 1008 & 766 & $76 \%$ & 536 & 218 & 134 & 346 & 124 \\
\hline
\end{tabular}

Table 1. Students' Participation

The students' participation in 4 years is shown in Table 1, we can see from the perspective of class attendance, there are only subtle differences between traditional offline learning and blended learning in the last 4 years, all close to $75 \%$. From the perspective of class discussion, students show a higher learning enthusiasm in blended learning, the number of students participated in classroom discussion is obviously higher than that in traditional offline learning. What's more, here are some activities only for the blended learning, such as chatting and forum. In summary, it is easier for students to attend to the classroom activities and have more opportunities to express their ideas in blended learning.

\section{Summary}

In this paper, we explore the application of blended learning in higher education on starC, the application results show that the blended learning is useful for teaching the course of software engineering and the teaching support tools are important element for blended learning. Using starC for blended learning can break through the limitation of time and space, while can stimulate students' learning enthusiasm, improve the learning efficiency. The blended learning improves learning efficiency from two dimensions: one dimension is depth, it provides more learning and communication opportunities for students, included entering into the system and access to resources, the opportunities to discuss and chatting and so on. Another dimension is width, the blended learning can cover more students and teachers.

Blended learning can improve the learning efficiency based on starC, although we have achieved certain effects in the attempt, there is still a defect in the process of exploration, how to adopt the personalized learning? Due to the learning difference among the students, it is difficult to meet the expectations of the curriculum for all students, this will limit the personalized development of student. So further study should be done on how to make blended learning adapt to personalized 
learning, if we can solve this problem effectively, not only can we cultivate the interests in learning, promote the ability of thinking, but also can provide personalized service and teach students in accordance with their aptitude.

\section{Acknowledgement}

This research was partially funded by the Specific funding for education science research by self-determined research funds of CCNU from the colleges' basic research and operation of MOE (CCNU16JYKX27, CCNU16JYKX031), the National Natural Science Foundation of China under Grant (No. 61505064), the Project of the Program for National Key Technology Research and Development Program (2013BAH72B01, 2014BAH22F01) and the Graduate student education innovation fund project (No. 2016CXZZ34).

\section{References}

[1] D. Kenwright, "Blended learning," Pathology, 44, Supplement 1, p. S5, 2012.

[2] M. Kaur, "Blended learning - Its challenges and future," Procedia - Social and Behavioral

[3] Sciences, 93 (2013), 612-617.

[4] P. Kharb and P. P. Samanta, "Blended learning approach for teaching and learning anatomy:

[5] Students' and teachers' perspective," Journal of the Anatomical Society of India, 65 (2016), 43-47.

[6] W. W. Porter, C. R. Graham, K. A. Spring, and K. R. Welch, "Blended learning in higher education: Institutional adoption and implementation," Computers \& Education, 75 (2014), 185-195.

[7] M. Ari and M. C. Taplamacioglu, "Web-based blended e-learning for adults; a case study," Procedia - Social and Behavioral Sciences, 47 (2012), 1028-1033.

[8] Buran and A. Evseeva, "Prospects of blended learning implementation at technical university," Procedia - Social and Behavioral Sciences, 206 (2015), 177-182.

[9] M. Clement, L. Vandeput, and T. Osaer, "Blended learning design: a shared experience," Procedia - Social and Behavioral Sciences, 228 (2016), 582-586.

[10]L. Nazarenko, "Blended learning vs traditional learning: what works? (a case study research)," Procedia - Social and Behavioral Sciences, 200 (2015), 77-82.

[11]L. D. Kantar and A. Massouh, "Case-based learning: what traditional curricula fail to teach," Nurse Education Today, 35 (2015), 8-14.

[12] S. Kumar and R. Toteja, "Print to digital: a study of students' psychosomatic cost in traditional and e-learning," Procedia - Social and Behavioral Sciences, 67 (2012), 553-560.

[13]W. Fan, "An experimental comparison of the flexibility in the use of thinking styles in traditional and hypermedia learning environments," Thinking Skills and Creativity, 7 (2012), 224-233.

[14]C. Wai and E. L. K. Seng, "Exploring the effectiveness and efficiency of blended learning tools in a school of business," Procedia - Social and Behavioral Sciences, 123(2014), 470-476.

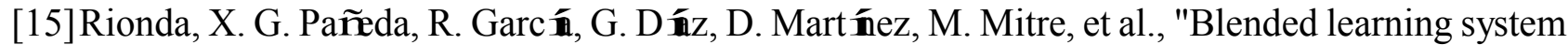
for efficient professional driving," Computers \& Education, 78 (2014), pp. 124-139.

[16] S. B. Dias and J. A. Diniz, "Blended learning in higher education: different needs, different profiles," Procedia Computer Science, 14 (2012), 438-446.

[17] Han and W. S. Shin, "The use of a mobile learning management system and academic achievement of online students," Computers \& Education, 102(2016), 79-89.

[18] M. Georgsen and C. V. Levstad, "Use of blended learning in workplace learning," Procedia Social and Behavioral Sciences, 142 (2014), 774-780. 